\title{
Los efectos perversos de la publicidad en la televisión franquista (1956-1975)
}

\author{
Mercedes MONTERO \\ Universidad de Navarra \\ mmontero@unav.es
}

Recibido: 04/02/2014

Aceptado: 10/03/2014

\begin{abstract}
Resumen
La publicidad hizo posible el desarrollo de la televisión en España. Gracias a ella, también, el país pudo evolucionar hacia el progreso económico más potente hasta entonces conocido. Junto con la sociedad de consumo, los anuncios televisivos aportaron una imagen más amable, más alegre y más fácil de la vida. La pequeña pantalla se convirtió enseguida en el primer medio de inversión publicitaria, lo que animó enormemente el anquilosado mercado español. Cuando el Estado franquista introdujo la televisión no podía saber que la publicidad cambiaría con tal radicalidad la vida diaria y la mente de los ciudadanos, conduciendo sus anhelos y aspiraciones por caminos muy distintos de los predicados por el régimen dictatorial. La apertura mental que obró la publicidad, hizo que los españoles mostraran una excelente disposición para la transición política hacia la democracia. A eso es a los que llamamos efectos perversos -o no buscados- de la publicidad en televisión.
\end{abstract}

Palabras clave: Publicidad, TVE, franquismo (1956-1975), consumismo.

\section{Perverse effects of advertising in francoist television (1956-1975)}

\begin{abstract}
Advertising made the development of Spanish television possible. Thanks to it, too, the country could evolve into the most powerful economic progress hitherto known. Along with the consumer society, television commercials provided a more friendly, happier and easier life. The small screen quickly became the primary mean of advertising investment, which greatly encouraged the Spanish market stagnant. When the Francoist state introduced television, it could not imagine that advertising would change daily life, the minds and aspirations of citizens so radicaly. All this contributed to the willingness shown by the Spanish for political change to democracy.
\end{abstract}

Keywords: Advertising, TVE, Franco (1956-1975), consumerism.

Referencia normalizada: MONTERO, Mercedes (2014): "Los efectos perversos de la publicidad en la televisión franquista (1956-1975)”. Estudios sobre el Mensaje Periodístico, Vol. 20, Núm. especial, pp. 139-156. Madrid, Servicio de Publicaciones de la Universidad Complutense.

Sumario: 1. Introducción. 2. Fuentes y Metodología. 3. Los años del patrocinio, los concursos y las subastas (1956-1969); 3.1. Los problemas de un mercado publicitario inmaduro; 3.2. Una publicidad sin criterios profesionales; 3.3. Por el consumo hacia la apertura mental. 4. Los años de la Gerencia (19691975); 4.1. La publicidad en el ojo del huracán; 4.2. La (mala) calidad de los anuncios televisivos; 4.3. El debate sobre la representación publicitaria del sexo. 5. Conclusiones. 6. Referencias.

\section{Introducción}

Este artículo es un estudio original sobre el mercado publicitario en televisión durante el franquismo, y de las consecuencias socio-culturales que desencadenó. La publicidad en la pequeña pantalla fue un factor indispensable para el desarrollo económico de España. Pero tuvo efectos secundarios más potentes e inesperados, que el régimen franquista no hubiera dudado de calificar como perversos: actuó como catalizador de una nueva mentalidad (modas, usos y costumbres) que modificó radicalmente la vida 
diaria de los ciudadanos. A lo largo de la historia, el desarrollo de determinados ambientes culturales ha precedido a la implantación de nuevas estructuras políticas. $\mathrm{O}$, como afirma buena parte de la historiografía anglosajona, "politics is shaped by culture" (Hunt\&Bonnell, 1989; Hunt, 1984: 88). Desde este enfoque parece evidente que la apertura mental que fueron dejando los mensajes publicitarios entre los espectadores, fue parte importante del trastoque de valores que se produjo en la sociedad. Este hecho contribuyó no poco al cambio desde los moldes de una sociedad autoritaria y jerárquica (en todos sus niveles), hasta la transición a un régimen de libertad política y autonomía personal. En España pudo darse la democracia después de cuarenta años de régimen dictatorial, porque los ciudadanos aspiraban en su mayoría a lograr una vida mejor. La publicidad televisiva funcionó desde el principio -sin buscarlo, probablemente- como barrera que frenó el interés por ideales del régimen, y los sustituyó por otros mucho más atractivos. La sociedad española intuía o entreveía sus nuevas aspiraciones gracias a la publicidad televisiva, y debió hacerse evidente que esos anhelos se hallaban más relacionados con la democracia que con el franquismo. Así, a pesar de los problemas que hubo que superar a partir del 20 de noviembre de 1975, siempre hubo una mayoría silenciosa que estuvo a favor del cambio, a pesar de los partidos, de los sindicatos, de los políticos, del terrorismo, de las mismas instituciones e incluso de los medios de comunicación.

La publicidad interactúa con la economía y entra en crisis cuando esta decae. Entre 1961 y 1974 la tasa de crecimiento del PIB en España fue del 7\%, un hecho excepcional por su cuantía y por su duración (García Delgado, 1994: 177 y 180). Fue el periodo de máximo crecimiento experimentado por el país en su historia contemporánea. Durante el franquismo desarrollista, la economía española "se unió definitivamente al club de los países industrializados" (Nadal, 2003: 238).

En esta coyuntura la televisión se convirtió muy pronto en el medio publicitario por excelencia. En 1960, sólo existían en el país 250.000 aparatos, frente a los casi dos millones de Francia (1.920.000) y a los dos millones bien pasados de Italia (2.124.000). Pero en España el promedio de espectadores era de diez personas por cada aparato, pues pronto se pusieron en marcha los tele-clubs en pueblos y ciudades: una manera colectiva de ver la televisión. Una década después, en 1970, el número de receptores había crecido hasta casi los seis millones (5.800.000). Pero la televisión, como el resto de los medios, carecía de datos fiables sobre audiencia. Sin embargo, la venta de aparatos y su reparto geográfico ofrecían cifras de penetración tan extraordinarios que gracias a ello pudo nacer al fin un auténtico mercado publicitario en España. Entre 1939 y 1959, en un entorno de mera subsistencia, había sido imposible que arraigara una publicidad seria y profesional, aunque esta había iniciado ya su desarrollo antes de la guerra civil (Montero, 2012, 205-232).

\section{Fuentes y Metodología}

Las fuentes para hacer la historia del mercado publicitario español (a partir de 1960) se encuentran en los archivos públicos y en la revistas profesionales. Deberían estar también en los archivos privados de agencias, medios y anunciantes, pero este tipo de empresas dan poco valor, de ordinario, a su fondo documental. Quizá por eso la his- 
toria de la publicidad carece a veces del rigor que ya tienen otras áreas de la Historia de la Comunicación.

Si nos centramos en el mercado televisivo español, desde sus comienzos hasta 1975, encontramos material importante en el Archivo General de la Administración y en la propia Televisión Española. El primero guarda la documentación textual del Instituto Nacional de Publicidad, la Escuela de Publicidad y el Estatuto de la Publicidad, entre los años 1964-1973; además de algunos legajos con datos sobre tarifas, o partes oficiales de emisión, correspondientes a la temporada 1964-1965. Televisión Española conserva muchos anuncios a partir de 1965, pero en bruto y sin datar. Existen, por otra parte, documentos de censura de la Dirección General de Cinematografía del Ministerio de Información y Turismo, relativos a anuncios publicitarios de Televisión entre 1967 y 1975. Pero no constan en Archivo General de la Administración ni en el Fondo Documental de RTVE.

Las fuentes más importantes para nuestra investigación han sido las revistas profesionales del sector publicitario: Control de Publicidad y Ventas (1962) e IPMark, Información de Publicidad y Márketing (1963). Ambas recogen con detalle el desarrollo de la actividad publicitaria en el medio televisivo y ninguna de ellas ha sido estudiada hasta ahora como fuente histórica. Existen también libros que tocan el tema de la televisión franquista, como el de Antonio Jordán (1995), un conjunto de entrevistas en profundidad con los 'históricos' de la publicidad española; o el de Enrique Bustamante (2007) sobre la radio y la televisión en España entre 1939 y 2007. También otros que tocan aspectos parciales y que se irán citando a lo largo del trabajo.

En cuanto al método, hemos seguido una narración histórica basada en la cronología, pero enfocando cada periodo desde el elemento temático dominante, el que da su sentido último a todo lo ocurrido en ese espacio temporal.

\section{Los años del patrocinio, los concursos y las subastas (1956-1969) \\ 3.1. Los problemas de un mercado publicitario inmaduro}

Durante el franquismo pueden apreciarse dos etapas en la publicidad de Televisión Española. La primera abarca los años en que la adjudicación publicitaria se hizo por patrocinio, o concurso-subasta, entre 1956 y 1969. La segunda es la etapa en que TVE funda su propia Gerencia de publicidad y contrata directamente, sin intermediarios.

Entre 1956 y 1958 los gastos de Televisión Española (unos 20 millones de pesetas cada año), fueron 'prestados' por Radio Nacional de España (Anuario 1968, 27-29). Los únicos ingresos de la televisión procedían del canon por posesión de aparato, cuya cuantía oscilaba entre las 300 y las 500 pesetas, una cifra respetable para la época. Pero con tan pocos receptores en el mercado la cantidad conseguida era ridícula (Medina y Ojer, 2010: 334). Ni agencias ni anunciantes habían percibido todavía el enorme potencial publicitario del medio.

En este momento en que la televisión no interesaba a nadie, un belga afincado en España y dedicado a la publicidad, José (Joe) Linten, se arriesgó a entrar en el medio. El primer espacio publicitario que consiguió en TVE fue la retransmisión de un partido del Real Madrid. Después de aquel hecho aislado, que tuvo buenos resultados económicos para la televisión y para él mismo, su gran objetivo fue lograr un programa entero de calidad, producido y pagado por él, donde animaba a los anuncian- 
tes a insertar publicidad y lograba un buen negocio. Eso fue "Gran Parada", un espectáculo de variedades que gozó de enorme favor entre el público (Jordán, 1995: 49). Linten arriesgó y ganó, porque:

“en cuatro años escasos se produjo el 'boom' de la industria de televisores, [que] coincide con la guerra de los electrodomésticos, con el año de las sopas, con la época de las bebidas gaseosas. Todos irrumpen en el mercado y la televisión se convierte en el único medio con una audiencia millonaria. Algunos partidos de futbol son vistos por siete millones de españoles, cifra que sobrepasa alguna corrida de toros. Es un hecho histórico: nunca hasta entonces siete millones de españoles habían estado unidos por una sola vez en veinte siglos" (Control de Publicidad y Ventas, 86: 10)

Unidos por el futbol o los toros, pero también observando los efectos maravillosos que producía beber Coca Cola, el tono cosmopolita de la tónica, o la variedad de chocolates que ofrecía el sector alimentario. Otros siguieron el ejemplo de Linten entre 1956 y 1960. Uno de los anunciantes más activos fue por ejemplo Nestlé, que patrocinaba programas completos (Linten buscaba distintos anunciantes, no uno en exclusiva). A través de su jefe de publicidad, Jordi Garriga, bajo el seudónimo de Jorge Leman, Nestlé estableció una productora de televisión "independiente" de la empresa, llamada Tele Man, Realizaron programas tan importantes en su momento como "Esta es su vida", "Reina por un día", "Ayer noticia hoy dinero", o "Adelante el inventor". No es casualidad que Nestlé, una potencia en la producción de productos de gran consumo deseara cuanto antes anunciarse en televisión. Los hechos estaban demostrando que la audiencia reaccionaba positivamente ante los nuevos bienes que aparecían en televisión, y los adquiría en mayor cantidad que antes. Los programas patrocinados continuaron hasta 1964, mientras que el canon por tenencia de aparato receptor terminó en 1965.

Podemos afirmar por lo tanto que, cuando la televisión era todavía un negocio arriesgado, fue la publicidad la que se hizo cargo de las dificultades. Evidentemente no por altruismo, sino porque funcionaba. Agencias y anunciantes reaccionaron favorablemente, dedicándose con entusiasmo y colaboración decidida a promocionar, prestigiar y valorar el nuevo medio. Aún se hallaba la televisión en su infancia pero ya resultaba rentable invertir en ella. Esa televisión primitiva fue creciendo en proporciones vertiginosas. Podemos ver una muestra de ello en la siguiente tabla:

Tabla 1: Número de aparatos entre 1958 y 1970

\begin{tabular}{|c|c|c|c|c|c|}
\cline { 2 - 6 } \multicolumn{1}{c|}{} & $\mathbf{1 9 5 8}$ & $\mathbf{1 9 6 0}$ & $\mathbf{1 9 6 5}$ & $\mathbf{1 9 6 8}$ & $\mathbf{1 9 7 0}$ \\
\hline $\mathbf{N}^{0}$ receptores & 40.000 & 250.000 & 1.750 .000 & 3.500 .000 & 5.800 .000 \\
\hline
\end{tabular}

Fuente: elaboración propia a partir Anuario TVE 1968 y Statisticals Yearbooks 1971

De cualquier manera, los ingresos por publicidad de TVE -aunque subieron enormemente- fueron, con todo, modestos entre 1957 y 1960:

Tabla 2: Ingresos por publicidad entre 1957 y 1960

\begin{tabular}{|c|c|c|c|c|}
\cline { 2 - 5 } & $\mathbf{1 9 5 7}$ & $\mathbf{1 9 5 8}$ & $\mathbf{1 9 5 9}$ & $\mathbf{1 9 6 0}$ \\
\hline Ingresos publicitarios & 200.000 & 5.000 .000 & 16.000 .000 & 34.000 .000 \\
\hline
\end{tabular}

Fuente: Medina y Ojer, 2010: 335 
Hasta 1960 no se dio cuenta el Estado franquista de que la televisión, además de crecer de manera exponencial, se estaba convirtiendo en el gran inductor de las opiniones en España. Fue entonces cuando decidió establecer sobre ella un mayor control. Aquí es cuando se dio cuenta de los efectos no buscados -o efectos perversosque estaba generando el nuevo invento entre los españoles. El Estado se hizo con el contenido de la publicidad (y de los programas) en sentido moral e ideológico. Pero cuesta creer que previera el cambio cultural que el mero consumo de los nuevos bienes y servicios iba a provocar en el ánimo de los ciudadanos. El Estado no se daba cuenta de que controlar moralmente los anuncios no era la cuestión. Seguía contemplando y permitiendo la publicidad como un modo imprescindible de financiar la televisión, sin percatarse de la potencia de las imágenes y el sonido unidos para potenciar el deseo de aspirar a algo mejor. Pero esa miopía fue una suerte para España.

En otoño de 1960 se creó la Junta de Televisión Española, encargada de la publicidad, que fue organizada según las normas propias de la Administración Pública. Así la adjudicación de espacios televisivos se realizó en forma de órdenes de publicidad y concurso-subasta (IPMark, 65: 24). Entre las temporadas 1960-61 y 1962-63, 1legaron a ser veinticinco las agencias adjudicatarias. Pero había tres bloques importantes: "Por un lado el coloso de la TV [...] Movierecord, seguido de sus agencias amigas, [...] Alas, Ancema, Rasgo, etc. De otro, y casi enfrentado con él, [...] el grupo de Publidis, Publi-Visión, V-60, Balena, Salvador, Carvis y alguna otra. Queda fuera de juego el grupito de Sagi, al que siguen Dardo, Estilo [...]" (Control de Publicidad y Ventas, 2: 1). El sistema propició de hecho el monopolio de Movierecord (la agencia de Linten) que llegó a controlar el 42\% de la programación de TVE (Jordán, 1995: 49$50)$.

TVE fue aumentado progresivamente sus tarifas, al comprobar que la demanda comenzaba a mostrarse ansiosa. Los espectadores por aparato se calculaban entre cuatro y seis en los programas habituales y hasta cuarenta en los programas especiales (futbol, toros, y los espacios "Gran Parada" y "Amigos de los lunes", realizado este último por la agencia Sagi). En noviembre de 1962, el 13\% de los hogares españoles disponía de televisor, lo que suponía prácticamente todas las familias con ingresos anuales superiores a 100.000 pesetas. Sobre ese porcentaje, un cálculo 'grosso modo' daba la cifra de cuatro millones de personas de toda edad con televisión en casa. Ningún otro medio podía ofrecer semejante mercado al anunciante (Control de Publicidad y Ventas, 12: 51).

Pero la televisión, sin embargo, tenía demasiadas debilidades. Salvo los espacios antes mencionados, el resto de la programación no era atractiva para los espectadores. Lo único que se salvaba era el telefilm norteamericano "Perry Mason", los programas patrocinados "Esta es su vida" y "Escala en Hi Fi" y otro producido por Adolfo Marsillach llamado "Silencio, vivimos". El resto carecía de calidad. Además solo existía un canal de televisión y la cobertura no abarcaba toda la península. Todo esto podía ser un freno para la publicidad y había que hacerla mejor para que "el público [no] vuelva la espalda a un medio que como quien dice acaba de nacer y tiene un campo limpio de obstáculos, como no lo tuvo ningún otro" (Control de Publicidad y Ventas, 3: 105). 
En este ambiente se produjeron las escandalosas adjudicaciones de 1963-64. Queriendo terminar con el monopolio de Movierecord, surgió otro aún peor. En el núcleo estuvo la aparición de una nueva agencia, Telesistemas, que logró las mejores espacios publicitarios a base de ofrecer por los ellos grandes cantidades de dinero, que ninguna otra agencia podía igualar. Las tarifas publicitarias subieron casi un $100 \%$, como podemos apreciar en la siguiente tabla de inversiones publicitarias en TVE:

Tabla 3: Aumento tarifas publicitarias 1961-1964

\begin{tabular}{|c|c|c|c|c|}
\cline { 2 - 5 } \multicolumn{1}{c|}{} & $\mathbf{1 9 6 1}$ & $\mathbf{1 9 6 2}$ & $\mathbf{1 9 6 3}$ & $\mathbf{1 9 6 4}$ \\
\hline Millones & 85.000 .000 & 213.000 .000 & 524.000 .000 & 901.000 .000 \\
\hline
\end{tabular}

Fuente: Bustamante, 2007, 60

Telesistemas fue una iniciativa de Joaquín Soler Serrano y José Mayá Ríus. La empresa estaba dada de alta en julio de 1963 . Se les adjudicó el $60 \%$ de los espacios publicitarios de la hora C, la más cara por su mayor audiencia (de las 21.45 a las 22 horas). Su planteamiento era disparatado y logró subsistir apenas un año (hasta diciembre de 1964), pero provocó una carrera suicida de precios en la que participaron las demás agencias. Al parecer nadie tuvo en cuenta la realidad de la demanda, prometedora pero todavía inmadura, incapaz de afrontar las desproporcionadas cifras que se pedían. Ante la imposibilidad de encontrar anunciantes, los precios empezaron a bajar en caída libre y los espacios publicitarios casi se regalaban. Estas 'gangas' disminuyeron la inserción publicitaria en los diarios de provincias. A finales de 1964 el entero mercado publicitario sufrió una tremenda conmoción como consecuencia de esa guerra comercial. Debido a sus propios errores de planteamiento, Telesistemas se hundió y los profesionales del sector, en colaboración con TVE, debieron adoptar rápidamente unos acuerdos para evitar el derrumbamiento de la televisión (Control de Publicidad y Ventas, 31: 19). Se produjo un compromiso entre adjudicatarios y medio para que esas nuevas normas estuvieran vigentes desde enero de 1965 hasta el 30 de septiembre de 1967. Básicamente la normativa se ceñía a tres puntos: reducción de un $40 \%$ del espacio televisivo dedicado a la publicidad, aplicación de unas tarifas fijas para los adjudicatarios y la desaparición, prácticamente, del sistema de subasta. Hasta entonces, la proporción de publicidad en TVE era de un 10\% del tiempo total de programación. A raíz de los acuerdos citados, esa proporción disminuyó hasta el 5\% (IPMark, 15: 7 y 3).

El año 1965 fue el de la estabilización del mercado publicitario español. Se hizo posible a partir de entonces planificar adecuadamente las campañas de los clientes. Las tarifas para un 'spot' de15 segundos en la hora $C$, quedaron fijadas en 75.000 pesetas. Se estrenó el segundo canal (UHF). Quedaba "una televisión repuesta de su gripe invernal, más tranquila, sin nervios, y con sus problemas solucionados hasta 1967" (Control de Publicidad y Ventas, 35: 1; 40: 4 y 15). En realidad el sistema se prorrogó -con subidas impopulares de precios en octubre de 1967 y octubre de 1968- hasta el mes de julio de 1969, cuando se presentó en público la nueva Gerencia de Televisión. A partir de entonces todas las agencias pudieron contratar la publicidad directamente con el propio medio, sin exclusivistas intermediarios. 


\subsection{Una publicidad sin criterios profesionales}

A pesar del enorme éxito que cosechaban entre el público los productos anunciados, la publicidad televisiva española era de muy baja calidad. Esto supone una señal del escaso criterio del consumidor español por aquellos años. Quizá es que -acostumbrados al desierto del consumo- los ciudadanos quedaban cautivados por la diversidad y utilidad de tantas cosas que no conocían. El mismo hecho de los tele clubs ya aludidos nos habla de una especie de ansia colectiva por aquel nuevo cambio en su vida. El hecho es que las agencias españolas de la publicidad estaban anticuadas y actuaban con escasa profesionalidad. En 1965, cuando en otros países el dibujo animado ya no se usaba, en España se encontraba en pleno auge. Además, los 'spots' nacionales duraban 15 segundos, cuando en lugares "con un uso racional de la televisión" la media era de 30 ó 60. Aquí seguíamos anclados en el 'jingle', una fórmula vieja, gastada y ya olvidada en el universo publicitario exterior. En opinión de los creativos españoles, nuestros modos de hacer constituían "grandes e imperdonables errores" y en buena medida achacaban su abusiva práctica a la ceguera de los anunciantes (IPMark, 20: 18). El hecho es que en 1965 la televisión en España era ya el medio publicitario más importante. Y se trataba de un medio 'de auténtico interés nacional': la industria hispana, si quería mantenerse, ya no podía prescindir de ella. La televisión era plataforma de lanzamiento y de persistencia en el mercado (IPMark, 22: 45). Los 15 segundos de duración de un 'spot' servían únicamente para lanzar un producto. Según Francisco Izquierdo, de la agencia Izquierdo \& Nogueras, con tan escaso tiempo solo era posible

"crear marca y no explicar cualidades [...]. Los nefastos 15 segundos, sin tarifas para 30 o para 60 , han convertido técnicamente a la televisión española en un vertedero de recordatorios, prácticamente inutilizables, cuando el problema es de argumentación, de creación de un nuevo consumo, o de cambio en los hábitos del público" (Control de Publicidad $y$ Ventas, 36: 7)

Existía una corriente fuerte entre las agencias favorable a los anuncios de 30 segundos. Pero el problema eran los anunciantes (o fabricantes), que querían asegurarse el mayor número posible de impactos. Y, evidentemente, con esa mentalidad, un 'spot' de 15 segundos era más barato y por lo tanto podía ser emitido muchas veces más que otro de 30 o 60. Control de Publicidad y Ventas se lamentaba de este hecho y se preguntaba por qué nadie velaba por la mejor inversión del dinero (40: 11). Al parecer, solo un $10 \%$ de los 'spots' podían calificarse de buenos. Los demás carecían de originalidad, de sentido artístico y publicitario. Todo era improvisación (45: 63). Un buen anuncio debía ser, ante todo, una buena producción audiovisual: con buen sonido, nítida imagen, actores convincentes. Por este lado las posibilidades en España no eran de momento muchas. Pero además, un buen anuncio debía 'vender' el producto con un slogan adecuado, y no recrearse en cuestiones totalmente ajenas a las propiedades de aquel objeto. Es decir, entretenerse en bonitos paisajes o simpáticos chistes, olvidando lo esencial. Por otra parte, era muy normal copiar las ideas de otros, si estas habían producido resultado. En resumen, y a pesar del éxito evidente de la publicidad, los espectadores podían llegar a cansarse de tanta banalidad: este era el mensaje de los creativos. 
A la propia TVE tampoco parecía preocuparle mucho la calidad de sus anuncios. Instalada en un cómodo monopolio, concebía la publicidad como simple fuente de ingresos. Sus gestores carecían de sensibilidad creativa en absoluto, aunque fueron adquiriendo ciertos conocimientos técnicos. Una de sus prácticas habituales fue vender espacios publicitarios a las agencias adjudicatarias sin que éstas conocieran previamente la programación, de tal manera que era imposible asegurar una cifra aproximada de audiencia al anunciante porque no se sabía si su anuncio iba a emitirse después del telefilm "El Santo" (buena suerte) o tras un documental sobre la vida de las abejas. En tal contexto resultaba lógico que pocos de ellos se arriesgaran más allá de los 15 segundos. Casi ninguno se planteaba sus inversiones televisivas de acuerdo con un plan de marketing activo y especialmente diseñado para su empresa. La mayoría seguía dedicando fabulosas sumas sólo guiados por la impresión "de que la televisión machaca, que la gente no tiene más remedio que tragarse el mensaje" (Control de Publicidad y Ventas, 50: 71). Lo cual incomodaba mucho a los creativos, pero era la pura verdad.

\subsection{Por el consumo hacia la apertura mental}

Mientras tanto, la sociedad española convivía pacíficamente con los resultados de la publicidad televisiva, sin que nadie se planteara los cambios de actitud que se estaban produciendo en ella. Anunciantes y publicitarios apostaban en 1967, sin posible error, por convertir cuanto antes al país en una auténtica sociedad de consumo de masas. Y con eso querían decir una sociedad occidental, europea, norteamericana, respetuosa de la libertad, ¿democrática?. Aunque de momento la idea todavía parecía inaplicable en profundidad, lo fundamental era que -como tendencia- el mercado caminaba hacia ese modelo concreto a pasos agigantados, con gusto y satisfacción. Un gráfico sobre la posesión de bienes en los hogares españoles, nos muestra la íntima relación alcanzada entre la publicidad en televisión y la sociedad de consumo.

Tabla 4: Posesión de determinados bienes en los hogares hispanos

\begin{tabular}{|l|r|r|r|}
\hline Bienes & $\mathbf{1 9 6 0}$ & $\mathbf{1 9 6 4}$ & $\mathbf{1 9 6 6}$ \\
\hline Teléfono & $12 \%$ & & $23 \%$ \\
\hline Televisión & $1 \%$ & $13 \%$ & $32 \%$ \\
\hline Coche & $4 \%$ & & $12 \%$ \\
\hline
\end{tabular}

Fuente: Información de Publicidad y Marketing, 41: 83

Según la revista IPMark el aumento de los televisores era "lógicamente espectacular", debido a su novedad y sobre todo a que se había convertido "en símbolo de status" y expresaba "un cambio muy notable de hábitos familiares". Por otra parte, había que tener en cuenta su precio, que había disminuido de manera notable, cosa que no había ocurrido con otros bienes y servicios (IPMark, 41: 83).

Los propios hombres del régimen no dudaban en ligar el desarrollo económico a la publicidad televisiva. Así se expresaba el 22 de noviembre de 1967 Jesús Aparicio Bernal, Director General de RTVE: 
"En una economía dinámica, como está empezando a serlo la española, la publicidad es algo imprescindible, y en ese proceso publicitario, la propia economía nacional exige que participe un medio como la televisión, que ha permitido crear un auténtico mercado nacional para productos que anteriormente eran solo locales o comarcales. TVE no es ajena a las nuevas formas de los anuncios, a su mayor fuerza, y al hecho de que numerosas industrias hayan entrado con buen pie en la fabricación de grandes series, solo posible cuando se amplía el mercado y se abren nuevos canales de venta" (IPMark, 50: 70).

Como ya sabemos además de fomentar los productos españoles, los 'spots' tentaban con modos de vida que llegaban más allá de los sueños. Mucha ambientación publicitaria rebasaba lo extraordinario, lo sensacional, lo 'súper':

"cuando se hace publicidad para [...] personas de vida media, que somos la mayoría, se nos ponen delante de nuestros ojos o narices fenomenales coches, pisos de súper lujo, ambientes de la Costa Azul. [...] ese mundo publicitario que cada día forma y conforma más nuestra manera de ser [...]" (IPMark, 79: 15).

Es decir, se abrían espacios mentales que hasta entonces ni se sospechaban. Todo ello quedaba bien definido en un artículo publicado por Control de Publicidady Ventas en 1967:

"[a la publicidad] no se le puede negar la virtud en España, de haber contribuido a hacer morder el polvo a las secuelas fantasmales de una 'lucha de clases' recalcitrante, para imponer como nueva y sana actitud mental, en las gentes, el concepto de 'lucha de standings'. Y todo ello a la 'chita callando', en solo diez años de encaramarnos a los trapecios de la acción comercial competitiva, previniendo y padeciendo los sobresaltos de un mercado nacional que de hambrienta demanda pasó a ser, cuando menos lo esperaban muchos, de multiforme y angustiosa oferta (estimulantemente angustiosa, se entiende), para los industriales que poseen una cuarta dimensión no autodidáctica. El lápiz de labios publicitario diseñó una atractiva sonrisa sobre las esquinas grises de la vieja España prometiendo al humilde todos los bienes de este mundo a cambio de saber o querer conquistarlos merced al esfuerzo de sus músculos o a las agudezas de su ingenio. El lápiz de labios es lo primero que utiliza la mujer para enardecer al hombre y extraerle de su inmovilismo fatalista; por eso la publicidad se convirtió en un arma más de la incipiente repoblación mental ibérica y con bastante buena fortuna, por cierto [...]. Nuestra publicidad no es, técnicamente, tan epidérmica como algunos lo suponen ni tan hedonista y carnívora como lo pretenden quienes desde hace mucho tiempo olvidaron darle cuerda a sus relojes" (Control de Publicidad y Ventas, 53: 67).

Según escribía el periodista Cándido en Pueblo (27 de mayo de 1969, página 61) todos los ciudadanos estaban contentos, en el fondo, con el "abrumador organillo publicitario", porque tocaba exactamente los mismos acordes que el resto de la 'gran orquesta'. El público, consciente o auto engañado, estaba haciendo el acompañamiento (Control de Publicidad y Ventas, 82: 61). Parece evidente que una nueva España se abría paso. Y no estaba en la mente una vuelta atrás. Al contrario, el propio Estado promovía este desarrollo y era además el propietario en exclusiva del ente fundamental para conseguirlo, la televisión. La publicidad en este medio no había sido un espejo de la sociedad, sino más bien un acelerador del cambio, pues proponía, en palabras de 
Nemesio Fernández Cuesta, un prohombre del franquismo "buscar una paz confortable con sabor marinero", ofrecía "el genuino sabor que conquista", incitaba "a entrar en un mundo aparte", en una "comodidad diferente" e incluso animaba a "aparcar nuestra fantasía en el lugar exótico que siempre soñamos” (La Publicidad..., p. 114).

Para el escritor y periodista Lorenzo López Sancho, la publicidad televisiva descubría nuestras verdaderas necesidades y obligaba a reconocer nuestros deseos más profundos. El wisky DYC por un lado, por otro los modernos vasos ofertados por los grandes almacenes, nos habían llevado a olvidar costumbres pueblerinas y a obsequiar a los amigos al estilo inglés y francés. Eso era una elevación del gusto de la gente y eso se lo debíamos a la publicidad (La Publicidad..., p. 143).

Todo esto lo sabían bien los profesionales del sector. Y alguno de ellos animaba a sus colegas a pensar en serio "cual queremos que sea nuestro papel en la sociedad". Esto en concreto se lo planteaba Marçal Moliné, uno de los jóvenes publicitarios creativos más brillantes del momento. En un artículo muy del 68, trufado con abundantes citas de Jean Paul Sartre y Daniel Cohn-Bendit, Moliné abordaba la conciencia del publicitario de izquierdas (quizá hablaba de su caso), para el cual la inmensa mayoría de la publicidad era alienadora y antisocial. Pero, argumentaba, no había que hacer publicidad para solucionar los problemas de venta, aunque fuera eso lo que nos habían aprendido. Lo que el publicitario debía hacer era convertir su actividad "en una experiencia de laboratorio, en una plataforma para adquirir unos conocimientos, un profesionalismo, una necesaria habilidad en comunicar que juega un papel de primerísimo orden en cualquier sociedad, sea cual sea su estructura”. ¿Habilidad en comunicar qué?, habría que preguntar a Moliné. No, según él mismo decía, las cualidades de venta de un producto; tampoco nada relacionado "con el sistema económico en que vivimos", pues de ese modo era imposible ir contra "ideas opuestas al sistema" (Control de Publicidad y Ventas, 72: 67). ¿Entonces, qué era lo que según Moliné había que comunicar a través de la publicidad? Parece que en la cabeza y en la voluntad del joven creativo bullía la necesidad de dar la vuelta a la mentalidad social. Y lo exponía con pasión, aunque de una manera críptica, evidentemente. En aquellos momentos, y en las revistas técnicas como eran IPMark y Control de Publicidad y Ventas, se podían criticar las tarifas publicitarias de TVE, o incluso hablar descarnadamente de los vicios de nuestros anuncios. Pero no se podía animar a desmantelar el sistema social, aunque de hecho eso mismo es lo que estaba ocurriendo. Y muchos creativos lo sabían. No podemos olvidar que ya eran los años de las revoluciones culturales, que deseaban echar por tierra todo el sistema socio-cultural heredado del pasado. Es lógico que sus ideas empezara a influir entre los más jóvenes de la profesión debido al potente motor configurador de las mentalidades que veían en su profesión.

\section{Los años de la Gerencia (1969-1975)}

\subsection{La publicidad en el ojo del huracán}

Mientras todas estas corrientes bullían en la trastienda de los anuncios, algo mucho más prosaico, como el modo de contratar la publicidad, era la preocupación principal de TVE. La contratación directa comenzó enseguida a dar espléndidos resultados en cuanto a número de 'spots' y beneficios ... para TVE. Las cifras comparativas de no- 
viembre de 1968 (sistema de adjudicatarios) con noviembre de 1969 (sistema de Gerencia) no dejaban lugar a dudas, como pone de manifiesto el siguiente cuadro:

Tabla 5: La publicidad en TVE (noviembre 1968 y 1969)

\begin{tabular}{|c|c|c|}
\hline $\mathbf{1 9 6 8}$ & $\mathbf{1 9 6 9}$ & Diferencia \\
\hline 423.621 .000 & 525.261 .569 & +101.640 .569 \\
\hline
\end{tabular}

Total estimado en pesetas. Fuente: Información de Publicidad y Marketing, 76: 49

A pesar de las críticas, la Gerencia pronto se manifestó como un sistema mejor para todos los sectores profesionales. De este modo, a partir de 1970, las revistas profesionales de publicidad se centraron en aspectos más cualitativos. El verdadero tema de fondo durante los años 70 fue el consumismo. Y directamente relacionado con él, las críticas y el malestar de todos - gobierno, intelectuales, público, publicitarios, anunciantespor el tipo de sociedad que se estaba generando, el excesivo número de anuncios y la ínfima calidad de estos. El ministro de Información y Turismo, Alfredo Sánchez Bella reconocía abiertamente en 1970 que para el desarrollo económico y social del país no se podía prescindir de la publicidad en TVE, una actividad que servía a los intereses de la industria, del comercio y de los servicios (IPMark, 76: 20). El ministro tuvo también que responder a varias preguntas de los procuradores en el seno de las Cortes, en un debate que se adivina tenso. Quizá el régimen franquista intentaba reaccionar, con evidente retraso, contra el cambio sociocultural que ya era manifiesto en España. Es posible que algunos se plantearan eliminar la publicidad. Sánchez Bella manifestó la imposibilidad de que TVE cubriera sus gastos sólo a cargo de los presupuestos del Estado; añadió que tampoco se quería volver al canon. Por ello, la publicidad era indispensable, aunque "no deseamos una cantidad excesiva [...]". Sánchez Bella se vio en la tesitura de dar un tanto la razón a los sectores más enemigos de la publicidad, afirmando su deseo de eliminar la carga materialista de los anuncios televisivos y fomentar, en cambio, su contenido artístico, pues la sociedad española no debía ser bajo ningún concepto una mera y ramplona comunidad de consumo (IPMark, 78: 9).

El gobierno español, sin embargo, era un problema pequeño comparado con la caterva de intelectuales pseudo marxistas o totalmente marxistas que pululaban por aquellos años en los círculos culturales del país. Uno de sus cometidos favoritos parecía ser el ataque indiscriminado contra la publicidad. Se la acusaba de generar situaciones de alienación, de manipular, de coartar la libertad, la imaginación y la personalidad. Los economistas partidarios de la socialización (un eufemismo para referirse a los marxistas) consideraban sus inversiones como un despilfarro intolerable, a beneficio de oscuros intereses particulares y no de la entera sociedad (IPMark, 126: 35-39). Algunos jóvenes antropólogos la juzgaban como el ritual mítico de la sociedad secularizada (Control de Publicidad y Ventas, 136: 58). En las revistas profesionales no faltaron las opiniones autorizadas contra esta marea. En 1974 Joaquín Lorente, por ejemplo, se refirió al "tonto grupito de intelectuales de turno que critican constantemente la publicidad, excepto a la hora de anunciar su libro, exposición o conferencia" (Control de Publicidad y Ventas, 135: 60). Por las mismas fechas, en una entrevista, Manuel Fer- 
nández Areal aseguraba que la publicidad era un gran despertador del deseo de compra; y que las necesidades que creaba, muchas de ellas, bien creadas estaban. Y añadía: "es una lástima [que alguna gente] se esté entonteciendo. Pero si no existiera publicidad se entontecería por algún otro procedimiento. Es un problema de formación" (Control de Publicidad y Ventas, 136: 58). Luis González Seara defendía su potente factor educativo afirmando que "hay mucha más reflexión y más cuidado en la composición de cualquier anuncio de un periódico que en la redacción de sus editoriales o artículos de fondo" (IPMark, 126: 47-48).

Entre unas cosas y otras, la profesión publicitaria se debatía en un ambiente de ebullición contradictoria según pasaban los meses. A ello contribuyó sobremanera la honda crisis creativa que se abrió en aquellos años. Los publicitarios aborrecían los obligados 15 segundos, a los que culpaban de todo, y reclamaban más tiempo como condición sine qua non para aumentar la calidad y no seguir provocando la reacción crítica del público. En este sentido, escribía Ricardo Pérez en IPMark:

"Estamos minusvalorando el medio. La TV es algo más que un medio para hacer marca.

Si solo se quiere salir en televisión a como de lugar, que nuestra marca se oiga y nada más, [...] minusvaloramos la televisión. Es un medio explicativo, demostrativo, argumentativo. $\mathrm{Su}$ idoneidad no radica solo en su gran cobertura y rentabilidad sino principalmente en su carácter audiovisual, en todos los recursos que pone a nuestra disposición. Para repetir y que suene, mejor la radio" (IPMark, 77: 26).

\subsection{La (mala) calidad de los anuncios televisivos}

La televisión y la publicidad compartían el desagradable papel de 'cabezas de turco' en todos los ataques que se hacían por doquier a la sociedad de consumo, las consecuencias del capitalismo y las demás formas de denominar a la realidad social del momento. Parecían todos de acuerdo en calificar a la publicidad televisiva como algo atosigante y lesivo para la libertad individual. Como hemos visto, los profesionales achacaban todos estos ataques a los 'spots' de corta duración. "Por razones más o menos justificadas -decía IPMark- la mayor parte de nuestros 'spots' son de 15 o 20 segundos. Y muchos de ellos no son buenos. Tienen exceso de palabras, son gritados, machacones, repetidos hasta la saciedad. Y por ahí nos vienen parte de nuestros males" (IPMark, 104: 12-14). Los impulsores de una nueva creatividad fueron un grupo de agencias y profesionales jóvenes, la mayoría de Cataluña. Ellos organizaron el primer Festival Nacional de cine publicitario, que se celebró en Barcelona, en la sede de la Feria de Muestras, entre el 7 y el 9 de junio de 1971. Se presentaron 220 películas, de cine y de televisión. La intención y el deseo de los organizadores era dignificar la calidad de la producción española. Entendían por calidad la evaluación de los conceptos de creatividad y comunicación de los anuncios, así como la adecuación y aportación artística de la realización. No se entraba a juzgar la eficacia comercial. Se encontraban en el Jurado varios de los publicitarios que serían posteriormente, en los 80 , los reyes de la creatividad española y del mundo, como Joaquín Lorente, Marçal Moliné o Leopoldo Pomés.

El evento levantó las iras de otra parte de la profesión, la de los más antiguos en el escalafón, los que llevaban toda la vida en publicidad y eran en buena medida hom- 
bres hechos a sí mismos. Los publicitarios se dividieron profundamente, con mutuos y nada elegantes reproches y agravios. Pero el festival siguió adelante durante varios años, contra viento y marea (Control de Publicidad y Ventas, 105: 113-115; 107: 4).

Realmente era muy necesario que la publicidad mejorara. En 1973 se presentaron 28 películas españolas al XX Festival Internacional de Cine Publicitario de Cannes. Ninguna de ellas pasó la selección previa. Algunos enardecidos hablaron de injusticia. Otros afirmaron que acerca de nuestra participación, lo mejor era guardar silencio, tan bochornosa había sido. España había dado la impresión de ir con retraso. Seguíamos con las películas cortas, los motivos demasiado localistas, la falta de ritmo, las pésimas actuaciones, el mal sonido y sobre todo, la gratuidad, es decir, 'spots' en los que el producto anunciado no tenía la menor relación con las imágenes que se mostraban: "Magníficas películas pero totalmente gratuitas. Como la de Terry" (Control de Publicidad y Ventas, 131: 35 y 43). Pero la crítica más acerba contra los anuncios españoles de Cannes fue la de Marçel Buxaderas, entonces un joven publicitario de la agencia Climax, que en 1974 fundaría BCK y que se uniría a la multinacional Alliance International en 1983. La cita es larga, pero su interés es máximo:

"El último certamen del film publicitario de Cannes ha evidenciado como casi siempre por parte española, un verdadero desastre creativo [...].

"[...] la estruendosa salva de silbidos, rítmica y creciente, las irresistibles caídas en el más profundo y letárgico sopor, o la franca huida en masa, y por piernas, de la sala del Festival ante la proyección de películas españolas, no fueron las clásicas y turbias maniobras, con fines oscuros, llevadas a cabo por agentes exteriores. No. Fueron reacciones espontáneas y naturales, directamente surgidas de una cordura y de una salud mental geniales.

"[...] esta fundamental y solemne debacle no puede cargarse en las simples, blancas e inocentes espaldas de quienes, de algún modo, nos representaron con sus producciones, sino que cae dentro del ámbito de la más plena responsabilidad de todo el glorioso estamento mercadológico nacional. Aquí no se salva nadie.

"Porque si alguna cosa hicieron, [...], nuestros queridos representantes, es precisamente 'representar' ante un auditórium mundial la auténtica realidad de nuestra filosofía, nuestra profesionalidad, nuestra técnica, nuestros medios y nuestros condicionamientos publicitario-comerciales. Y de la peor manera. Porque $[\ldots]$ ¿tenemos alguna cosa más interesante que decir? [...] ¿creen ustedes que en todo el amplio espectro de la publicidad española 73 hemos hecho cosas que mostrar?

"Así, del modo que venimos haciendo nuestras cosas -la publicidad es solo una de ellas y no ciertamente la más importante-, con un constante miedo al fracaso, sin la más mínima pizca de humor, agarrados a las sillas de nuestros cargos y privilegios, presidenciales o funcionarios, soportando el trabajo y el destino como un calvario (donde se va a sufrir y no a construir divirtiéndonos), sin diálogo de ningún tipo -ni posibilidad de realizarlo-, sin imaginación ni iniciativas, descargando todo el peso de nuestro poder y represiones sobre el más débil -llámese proveedor, inferior jerárquico, consumidor- sin saber de donde venimos, qué diablos estamos haciendo y donde demonios vamos a parar, resentidos, disgregados, individualmente angustiados, acumulando frustración tras frustración (con las mejores, más sanas y más profesionales ideas durmiendo siempre en los cajones o tiradas con rabia a la papelera) así, amigos míos, ¿quieren ustedes decirme cómo ha de ser nuestra publicidad? ¿Y cómo han de ser y ver la luz tantas y tantas otras cosas?" (Control de Publicidad y Ventas, 134: 70) 
Una declaración desgarrada de la situación de nuestra publicidad, pero no sólo. También era un grito desgarrado (y feroz) contra la críticas y presiones que debía soportar la profesión y -en general- contra la situación política y social de España. Los publicitarios españoles en general llegaron a 1975 aquejados de un hondo complejo de culpabilidad. Y eso, a pesar de lo que habían logrado haciendo publicidad, aunque fuera mal: cambiar en muy buena medida las aspiraciones y los modos de vida de toda una nación.

\subsection{El debate sobre la representación publicitaria del sexo}

Entre los problemas creativos que se planteaban los publicitarios españoles la utilización del sexo en los anuncios fue uno más. No se trató sobre ello de manera explícita en las revistas profesionales, porque la censura también funcionaba para ellas. Pero el número de IPMark inmediatamente posterior a la muerte de Franco dedica una buena cantidad de páginas a la cuestión, lo cual hace suponer que el tema no había surgido de manera repentina, sino que era la primera vez que se podía hablar abiertamente de él. También se llega a esta conclusión por determinados comentarios, algunos titulares e incluso ilustraciones de publicidad gráfica extranjera que fueron apareciendo eventualmente en Control de Publicidad y Ventas e IPMark a partir de 1969.

En junio de ese año sorprende el título de una columna sobre creatividad que escribía en Control de Publicidad y Ventas Joaquín Lorente: “¿Por qué anuncios con sotana si ahora gusta la minifalda?". Se trataba de una respuesta a un lector de La Vanguardia que se quejó de los anuncios televisivos sobre ropa interior femenina. Lorente explicaba que los anuncios 'sotana' eran los largos y sin propuestas claras y objetivas de venta, aburridos y sin interés para el posible comprador; en cambio, con las minifaldas se refería a aquellos otros 'spots' que sabían mostrar al espectador, de forma breve y contundente, los beneficios del producto publicitado. Y a partir del ejemplo, la pluma de Lorente derrapaba hacia el cuerpo femenino:

"No olvidéis que una mujer despierta más interés en el bar con la falda bien subida que desnuda en la playa. Y como no acostumbran a existir 'spots' con la falda bien subida (es decir, nos muestran el producto tal como es, sin atractivo), el público se aburre [...]. El público tiene razón, tiene derecho a una calidad. A una distracción. Hay intereses mucho más positivos por defender en su favor que el privarle de la visión de anuncios de sujetadores" (Control de Publicidad y Ventas, 82: 93).

Lorente estaba realmente enfadado... ¿quizá el anuncio era suyo?

En febrero de 1972 se presentó un estudio nacional sobre actitudes de la sociedad española ante la publicidad. Uno de los objetivos era determinar la reacción del público ante las apelaciones criptosexuales y ante las claramente pornográficas. Las conclusiones demostraban que el $24,2 \%$ de los ciudadanos opinaban que algunos anuncios atentaban contra la moral; mientras que un $11 \%$ deseaba más libertad: más libertad sexual $(3,1 \%)$, más exhibición de la mujer, $(7,1 \%)$ más libertad moral y religiosa $(12,1 \%)$ y más libertad de expresión $(16,7)$. Además, frente a un $25,4 \%$ que veía excesiva la publicidad que insertaba mujeres provocativas, un $62,4 \%$ opinaba que era normal mientras un $8,8 \%$ quería más La otra cara de la moneda era que -en el mismo estudio- se 
llegaba a la conclusión de que la publicidad gustaba mucho más a las clases bajas que a las altas, y a los habitantes del campo más que a los de la ciudad (IPMark, 101: 5657). Se podía deducir que el gusto por la sal gorda tenía cierto sabor barriobajero.

Este estudio se realizó tal vez porque ya hacía años que la publicidad estaba cambiando completamente sus formas de expresión: por etapas, según una progresión tan experta como inevitable, el desnudo estaba entrando en los medios de persuasión. Según escribía Miguel Angel Echevarría en IPMark "se comenzó con la lencería femenina, como excelente pretexto, seguido por los productos de belleza y por los desodorantes, para terminar con no importa qué. El sexo al servicio del tabaco, del aceite de oliva, de la moqueta, de la calefacción central, de los brandies". Para Echevarría, al principio se trató de un desnudo púdico, artístico, casi cándido, como el anuncio de los sujetadores Rosy que comunicaban "belleza e imagen sin necesidad de mostrar el producto". Vinieron después los sugerentes claro-oscuros "ya menos inocentes, mucho más evocadores", continuando con la escalada de los símbolos: "las bocas abiertas, los pulgares chupados, la evocación fetichista o sadomasoquista, las botas de cuero, los látigos y las cadenas". Mientras tanto, los censores de televisión vivían obsesionados por las axilas de las modelos cuando anunciaban desodorantes. Echevarría aseguraba que estaba naciendo "un nuevo grado de comunicación [...], de tal manera que podríamos preguntarnos si nuestros creadores sexuales solo piensan en esto". Y concluía:

“[...] para que el reto que nos presenta la comunicación erótica no lo transformemos en pornografía, no olvidemos que el sexo puede tratarse con oportunidad, moderación, buen gusto, como la campaña de 'oro en su piel', realizada por MMLB, muy lejos de los tristes ejemplos que diariamente nos ofrece el cine español con esa serie de ordinarias películas de los 'Landas' y otros actores de todos conocidos que hacen rugir los cines de barriada" (IPMark, 147: 69)

En aquellos años finales del franquismo la publicidad y la televisión compartían el desagradable papel de cabezas de turco en todos los ataques que se hacían a la sociedad de consumo, a las consecuencias del capitalismo o a la escalada del erotismo. Los comentaristas de prensa especialmente atacaban con crudeza la publicidad en televisión. Sin embargo, lo cierto era que el rasero moral para medir el cine o los mismos programas de la pequeña pantalla era mucho más permisivo que el utilizado para la publicidad (IPMark, 104: 7).

Ante los hechos que acabamos de examinar una conclusión evidente es que la revolución sexual del 68 llegó a España igual que a otras naciones. Y en aquellos años, mientras los buenos creativos realizaban anuncios donde el erotismo era tratado con oportunidad y buen gusto, en otras ocasiones proliferaban los anuncios soeces. Los profesionales se debatían entre la estrechez mental de los censores y el trabajo por llegar a soluciones creativas persuasivas y elegantes. Las burdas no requerían ningún esfuerzo, ya que recurrir al sexo como primera opción siempre ha sido un recurso facilón. Aparte queda la realidad de que era el cuerpo femenino el único que se exponía, lo cual nos habla de una mentalidad ciertamente machista, asumida pacíficamente por público y publicistas. 
De cualquier manera, este y otros temas estaban a punto de cambiar, pues empezaba a dibujarse una España muy distinta. En este contexto, entre el 2 y el 4 de diciembre de 1975, se celebraron en Barcelona unas Jornadas Técnicas de Publicidad. En ese foro, un mes después de la muerte de Franco, todo tipo de opiniones brotaron con espontaneidad y ciertas ansias de desahogo. Salieron a colación una y otra vez las críticas de los profesionales contra las circunstancias que habían hecho tan mala la publicidad española: los presupuestos escasos, la carencia de equipos técnicos de producción, la casi nula profesionalidad de los clientes, el éxito explotado al máximo cuando los 'spots' triunfaban, la política de no correr riesgos practicada por anunciantes y agencias, la censura arbitraria del gobierno...

"Estamos hartos - manifestó uno de los participantes- de que nos llamen malos y feos. Yo quiero que de una vez por todas me expliquen qué publicidad debemos hacer para contribuir al desarrollo de la nueva sociedad que todos pretendemos". Y uno de los ponentes, José Luis Segura, de Círculo de Comunicación, concluyó:

"Cuando el ciudadano esté educado con espíritu crítico y participe en la marcha del país, se abolirán los triunfalismos caducos y la creatividad publicitaria tendrá el derecho a manipular en un juego limpio, dentro de una sociedad pluralista".

La profesión encaraba la transición política a la democracia como la primera gran oportunidad para mejorar la comunicación comercial en general y la televisiva en particular. Pero quizá no eran conscientes de cambio que ya habían provocado con su publicidad. Los árboles les impedían ver el bosque: los árboles primeros, colocados apresuradamente, sin experiencia, ante una televisión hostil; los árboles segundos, los de las críticas consumistas y pseudo-marxistas cuando los profesionales empezaban a encontrar su camino; y los árboles terceros y más peligrosos, los de su propia falta de autoestima. Pero todo junto no anulaba su decisiva contribución para conseguir otra España.

\section{Conclusiones}

Podemos afirmar que la idea de introducir la publicidad en Televisión Española fue iniciativa de algunos pioneros que vieron en ello una oportunidad de negocio. Las autoridades gubernamentales solo buscaban poder financiar el nuevo invento, del cual no podían prescindir sin hacer de España un país tercermundista. No fueron capaces de ver las consecuencias que la publicidad tendría en el cambio de mentalidad de los ciudadanos. Es a esto a lo que hemos llamado los efectos perversos de la publicidad: los no buscados, ni deseados, ni siquiera intuidos y que -sin embargo- lograron un amplio cambio sociocultural en la nación. Sólo reaccionaron las autoridades franquistas en 1960, cuando notaron el impacto social del nuevo invento y decidieron controlar por ellos mismos las inversiones publicitarias. Para ello se adoptó un sistema propio de la Administración Pública del Estado, el concurso-subasta, que produjo de hecho una situación de monopolio. Y que casi hundió el entero sistema publicitario español a finales de 1964.

Hasta 1965 no logró estabilizarse el mercado publicitario en el nuevo medio, gracias a unas normas que adoptaron conjuntamente las agencias y TVE y que permanecieron intactas hasta 1969. Ese año el sistema se modificó por completo y nació la 
Gerencia de Televisión, que terminó definitivamente con los intermediarios y por tanto con el monopolio de hecho que ejercían algunas agencias adjudicatarias. A mediados de los años 60 los productores españoles ya no veían mejor manera de darse a conocer que la televisión. Era el medio por excelencia. La industria nacional necesitaba para su desarrollo del concurso publicitario de la Televisión. Sin ella, el desarrollo económico hubiera sido imposible. Así lo reconocieron varios ministros en el transcurso de esos años.

De cualquier manera, este desarrollo económico, social y cultural no dejaba de ser un pequeño-gran milagro, puesto que la publicidad televisiva era realmente de mala calidad. Los profesionales se quejaban de la falta de visión estratégica de los anunciantes, de sus mermados presupuestos y, sobre todo, de su insistencia en los anuncios de quince segundos. Hacia 1970 la sociedad de consumo era un hecho en España, pero lo era también la mala opinión que todas las instancias parecían tener sobre la publicidad televisiva. Los periódicos de provincias la acusaban de robarles su propia publicidad y por lo tanto, la vida; los políticos del régimen sentían que habían dejado cabalgar demasiado a la ligera al gran caballo del consumo, y que la sociedad española se les escapaba de las manos, estaba perdiendo su pretendida identidad, hipnotizada quizá por el materialismo que se veía en los anuncios televisivos. Porque era evidente que la publicidad estaba enseñando a los españoles mundos y modos de vida hasta entonces desconocidos, mucho más atractivos que los nacionales. Por su parte, la nueva intelectualidad más o menos izquierdista coincidía paradójicamente con el gobierno en sus ataques a la publicidad televisiva, debido al consumismo que se estaba expandiendo en la sociedad. Añadían estos, además, ataques contra el lucro que suponía la publicidad para los intereses privados de unos pocos y la alienación a la que sometía tanto anuncio en la pequeña pantalla. Todo ello impedía -según estos intelectuales- que las personas reaccionaran ante la realidad social, las injusticias y las desigualdades, pues se entontecían con el mero consumo y disfrute de los bienes materiales. Por su parte, los propios publicitarios vivían malos tiempos, de profunda división, entre los jóvenes que querían reaccionar ante la falta de creatividad y el desprecio que desprendía, al parecer, su profesión; y los más veteranos, quizá también preocupados pero menos dispuestos a arriesgar la posición adquirida.

El comienzo de una nueva era tras la muerte de Franco fue vista por todos como una oportunidad para mejorar. Gracias al consumo promovido por la publicidad televisiva, que hizo deseables y necesarios nuevos bienes materiales y provocó con ello nuevas costumbres, muchos españoles se sintieron bien dispuestos hacia el gran cambio: la transición política a la democracia. Algo que, ni en sueños, estaba en la mente de los promotores de la televisión cuando esta comenzó en España en 1956.

\section{Referencias}

BUSTAMANTE, Enrique (2007): Cultura y comunicación para el siglo XXI: diagnóstico y políticas públicas. La Laguna (Tenerife), IDECO.

CONTROL DE PUBLICIDAD Y VENTAS, revista mensual, del no 1 (octubre de 1962) al no 159 (diciembre 1975). 
GARCÍA-DELGADO, José Luis (1994): "La industrialización y el desarrollo económico de España durante el franquismo", en ARANGO, J.: La economía española en el siglo XX: una perspectiva histórica. Barcelona, Ariel.

HUNT, Lynn (1984): Politics, Culture and Class in the French Revolution. California, Berkeley University Press.

HUNT, Lynn \& BONNELL; Victoria (1989): The New Cultural History. California, Berkeley University Press.

INFORMACIÓN DE PUBLICIDAD Y MARKETING (IPMark), revista mensual, del $\mathrm{n}^{\mathrm{o}} 1$ (diciembre de 1963), al no 147 (diciembre de 1975).

JORDAN, Antonio (1995): Publicitarios de frente y de perfil. Madrid, Eresma.

LA PUBLICIDAD VISTA POR LA SOCIEDAD. Ciclo de conferencias organizado por el Instituto Nacional de Publicidad, con la colaboración del Sindicato de Prensa, Radio, Televisión y Publicidad y las Asociaciones Españolas de Anunciantes, Agencias Técnicas y Medios, Mayo-Junio 1971.

MEDINA, Mercedes y OJER, Teresa (2010): "El nuevo modelo de la televisión española". Comunicación y Sociedad, Vol. XXIII, No 2 .

MONTERO, Mercedes (2012): "La publicidad española durante el franquismo (19391975). De la autarquía al consumo". Hispania. Revista Española de Historia, vol. LXXII, núm. 240, pp. 205-232.

NADAL, Jordi (coord., 2003): Atlas de la industrialización en España, 1750-2000, Barcelona, Fundación BBVA/Crítica.

RTVE (1968): Anuario de TVE. Madrid. 